\title{
Narrativas visuales para enseñar el tiempo histórico desde una perspectiva rizomática
}

\section{Visual narratives to teach historical time from a rhizomatic perspective}

\section{Bazán, Sonia}

Sonia Bazán bazansa@gmail.com Universidad Nacional de Mar del Plata, Argentina

Clio \& Asociados. La historia enseñada Universidad Nacional del Litoral, Argentina

ISSN: 2362-3063

Periodicidad: Semestral

núm. 32, 2021

clio@fhuc.unl.edu.ar

Recepción: 01 Abril 2021

Aprobación: 19 Mayo 2021

URL: http://portal.amelica.org/ameli/jatsRepo/111/1112174008/ index.html

DOI: https://doi.org/10.14409/cya.v0i32.10186
Resumen: ¿Cómo enseñar a pensar sobre el tiempo, el tiempo histórico y sus múltiples componentes? Para recorrer sinuosamente esta inquietud nos apoyamos en la imagen, a la que entendemos como representación del tiempo. Como formadores de profesores en Historia para el nivel secundario y a partir del análisis y problematización acerca del uso de la imagen que realizaban las cohortes de practicantes 2018-2019, nos propusimos diseñar ejercicios de narrativas visuales para el desarrollo de lectura e interpretación de la imagen fija. Nuestras problematizaciones sobre las prácticas de enseñanza se proponen afianzar una formación inicial centrada en la educación históricosocial desde la búsqueda de la justicia curricular en los contextos donde los futuros profesores inician su ejercicio profesional y en este sentido la atención al tratamiento de la imagen como textofuente es una invitación a ampliar su formación con inclusión de la experiencia estética que implica ese lenguaje. En este trabajo presentamos en primer lugar el recorrido teórico sobre el tiempo y su enseñanza desde el cual fundamentamos nuestra la propuesta y luego desarrollamos los cuatro ejercicios para elaborar narrativas visuales.

Palabras clave: enseñanza, tiempo histórico, narrativas visuales, formación docente.

\begin{abstract}
How to teach to think about time, historical time and its multiple components? To navigate this restlessness sinuously we rely on the image, which we understand as a representation of time. As teacher trainers in History for the secondary level and from the analysis and problematization about the use of image by the cohorts of practitioners 2018-2019, we set out to design visual narrative exercises for the development of reading and interpretation of the image. Our problems about teaching practices aim to strengthen initial training focused on historical-social education from the search for curricular justice in the contexts where future teachers begin their professional exercise and in this sense we pay attention to treatment of the image as a source-text as in invitation to expand their training including the aesthetic experience involved in that language. In this work we present first the theoretical review about time and its teaching from which we base our proposal and then develop the four exercises to design visual narratives.
\end{abstract}

Keywords: teaching, historical time, visual narratives, teacher training. 


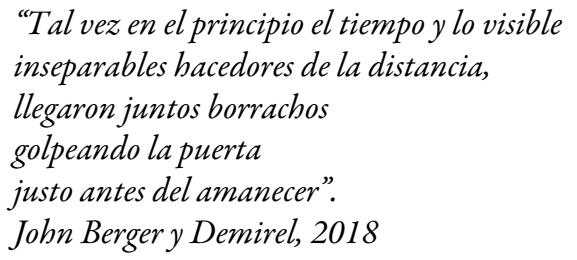

En tiempos de la televisión a demanda, de las maratones de series que inducen a la inmersión, de reels ${ }^{l}$ e historias fugaces en las redes, nos preguntamos ¿Cómo enseñar a pensar sobre el tiempo, el tiempo histórico y sus múltiples componentes? Para recorrer sinuosamente esta inquietud nos apoyamos en la imagen visual, a la que entendemos como representación del tiempo.

La preocupación por la enseñanza del tiempo histórico es uno de los ejes, sino el central, en la formación de profesorado, las investigaciones que se han desarrollado dan muestra de ello. ${ }^{2}$ En cuanto pensamos en enseñanza de las Ciencias Sociales, particularmente en la Historia, el componente temporal ocupa el lugar predominante entre los metaconceptos a enseñar y el cual es preciso alimentar y enriquecer teórica y metodológicamente. Desde aquí se origina la problematización que compartimos en este texto. El contenido surge como resultado de interpretaciones de un equipo de investigación y equipo docente, ${ }^{3}$ que tuvieron como objeto, la reflexión sobre las primeras prácticas de los futuros docentes, ${ }^{4}$ éstas dieron lugar a la investigación y a la propuesta que compartimos: las narrativas visuales como opción de mediación didáctica.

Nuestras problematizaciones sobre las prácticas de enseñanza tienen el propósito de afianzar una formación inicial centrada en la educación históricosocial desde la búsqueda de la justicia curricular en los contextos donde los futuros profesores inician su ejercicio profesional. Incluir este horizonte como base implica pensar la enseñanza de la Historia desde la interacción de tiempos, sujetos y espacios, desde las múltiples dimensiones que interrelacionan a los seres humanos y que nos permite entrelazar expectativas de formación que revitalicen la enseñanza de la Historia y las Ciencias Sociales con responsabilidad sociopolítica.

Los proyectos de clase y las prácticas iniciales de aula componen nuestro escenario de observación y reflexión desde los que producimos propuestas de cambios, transformaciones, fortalecimiento o que nos promueven a generar innovaciones. En este texto compartimos un recorrido en torno al uso didáctico de la imagen como representación del tiempo. Plantearemos en primer lugar algunas notas teóricas sobre esta perspectiva didáctica acerca del tiempo y su enseñanza (ítems I y II). Luego (ítems III y IV) proponemos cuatro ejercicios de narrativas visuales que emergieron como contenido de lectura, de inmersión estética, de recuperación de perspectivas de la historia cultural a partir de las que se conectan quien produce la imagen, qué produce quien mira y lo que se mira.

Las narrativas visuales tratan acerca del tiempo histórico, su transcurrir y su representación. Surgieron como consecuencia de nuestra indagación en torno al uso de las fuentes visuales por parte de los profesores practicantes quienes ya sea 
por incidencia de la historiografía en la valoración de las fuentes visuales, ya sea por estar atentos a la cultura audiovisual, a la influencia cross y transmedia en la que navegan, aprender y viven los jóvenes o por una preferencia personal, fueron desplegadas en sus proyectos de clase.

\section{Pasado, presente, futuro y ante ellos la lectura de imágenes}

La historia es narratividad y desde la modernidad ese relato se desarrolló centralmente en formato escrito, el texto escrito se convirtió en predominante sobre otros formatos como la oralidad, la producción visual y otras expresiones culturales (efímeras o no). Sin embargo, en esta oportunidad nos proponemos a recuperar la potencia de las capacidades narrativas (Bruner, 2013) que contiene la fuerza de la imagen como portadora de narratividad. Aquí la historia cultural y la historia del arte se convierten en bases necesarias para repensar la historia enseñada en una perspectiva de apertura hacia fuentes y recursos que se combinen y que vayan más allá de los textos escritos.

Formar un profesor que piense históricamente no es formarlo en el pensar disciplinar sino en el sentido del contexto, que, desde el pasado, desde la disciplina histórica pueda proyectar futuros pero que ante todo se presente como actor de lo cotidiano y un amante de la "reflexión hermenéutica" (Gadamer,1977) que convierte a la historia en la ciencia de la pregunta interminable.

Las narrativas visuales se presentan como artefactos culturales, motivo de análisis desde diversas perspectivas disciplinares, pero en este caso las pensamos como estrategia metodológica, de creación y producción por parte del futuro profesor. Reconocemos la potencialidad de la imagen como continente de información, portadora de narratividad y transmisora de la existencia de un mundo que se revela ante los ojos pero que precisa de ser interpretado. Desde la perspectiva benjaminiana de la Historia (1936 y 1947) y los aportes de Georges Didi Huberman, la imagen es portadora de tiempo. "Siempre ante la imagen estamos ante el tiempo...pero ¿qué clase de tiempo? ¿de qué plasticidades y de qué fracturas. ¿De qué ritmos y de qué golpes de tiempo puede tratarse en esta apertura de la imagen?" (Didi Huberman, 2011:31).

En las manifestaciones expresivas del lenguaje se expresa un relato. Entre las posibles opciones, elegimos las imágenes visuales como manifestación y narración sobre el pasado. ¿Qué elementos de la imagen se relacionan para construir historias y generar la narratividad? La imagen que contiene un relato se presenta como un "montaje de tiempos heterogéneos" que incluye "anacronismos" y nos propone intervenir en el diseño y producción de una narración a partir de la rugosidad de las imágenes, a partir del despliegue del tiempo contenido y resguardado en esa captura realizada por una creación estética sea a través de la fotografía o de la pintura. En esa obra, además, medió el ojo del quien fotografió o pintó la escena.

De allí que la imagen se constituye como una formalización científica capaz de ser contrastada por sus propios fundamentos gracias a que la naturaleza icónica de la imagen supone tres hechos esenciales: una selección de la realidad, un repertorio de elementos fácticos, y una sintaxis. (Peña Timón, 2003). Estos anticipan la naturaleza narrativa de las imágenes y, por consiguiente, el valor constitutivo propio de las narraciones y, sobre todo, su valor específico como 
relato: la existencia de narratividad. "La imagen narrativa hace referencia tanto a narraciones icónicas como a narraciones sonoras y audiovisuales. Pero desde el momento en que estos repertorios se presentan con una "intención", es decir, son producto de una "estrategia discursiva", hay que entenderlos como relato. Quiere esto decir, que la imagen narrativa es relato icónico y relato audiovisual..." (Peña Timón, 2003:77-79).

La narrativa visual es portadora de tiempo y se presenta ante nosotros como fuente y como recurso didáctico a partir del cual podemos lograr una posible representación del tiempo. Otras Ciencias Sociales, como la geografía cuentan con recursos como los mapas para representar el espacio, pero en el caso de la Historia las opciones tradicionales para representar el tiempo eran las líneas o frisos temporales. Basta recordar los ejercicios en papel cuadriculado y con reglas para ilustrar la proporcionalidad de escalas en una línea que suponía ser la máxima aproximación para entender las diferencias entre siglos, décadas y siglos. Sin embargo, la anotación de acontecimientos podía realizarse en tiempos puntuales, lineales o a lo sumo en el caso del friso temporal se incluía una coordenada que nos hacía pensar en los distintos espacios. Pero más allá de esos cruces de tiempo y espacio, la representación no podía salir de la bidimensional, no había duraciones, cambios o continuidades. Desde esta necesidad de representación del tiempo encontramos una potencia más en el trabajo con la imagen. En este sentido retomamos la interpretación de Walter Benjamin (1936) acerca de las transformaciones de la forma de percepción sensorial según los tiempos históricos. "Cada día cobra una vigencia más irrecusable la necesidad de adueñarse de los objetos en la más próxima de las cercanías, en la imagen, más bien en la copia, en la reproducción. Y la reproducción... se distingue inequívocamente de la imagen. En esta la singularidad y la perduración están imbricadas una en otra de manera tan estrecha como lo están en aquélla la fugacidad y la posible repetición" (Benjamin,1936:37).

Por esto entendemos que trabajar la imagen desde la perspectiva de las narrativas visuales nos permite articular con mayor complejidad y por tanto mayor posibilidad de explicación el concepto-horizonte y estructurante del "tiempo", un tiempo al que nos dedicamos quienes enseñamos historia y que en su multidimensionalidad y complejidad precisa ser pensado en forma y contenido a enseñar. Aquí es donde se nos presenta potable la figura del rizoma (Deleuze y Guattari, 1980) y desde un deslizamiento semántico la conectamos con la construcción de tiempo rizomático como opción para pensar su representación en la enseñanza.

\section{Los rizomas del tiempo representados en la imagen}

En Mil mesetas, Deleuze y Guattari (1980) desarrollan el concepto de rizoma que deslizamos hacia el ámbito de la didáctica para pensar acerca del tiempo histórico. El rizoma tiene características potables para nuestro interés porque se caracteriza por varios principios:

- Conexión y heterogeneidad. Se conecta por eslabones. Se puede descomponer internamente, en dimensiones. No hay unidades de medida sino multiplicidades y variedades de medida. 
- Multiplicidad. Una multiplicidad tiene dimensiones que no pueden aumentar sin que la multiplicidad cambie de naturaleza.

- Ruptura asignificante. Un rizoma puede romperse en cualquier sitio. Una de las características del rizoma es tener múltiples entradas.

Pensamos el tiempo histórico y su enseñanza como un ejercicio hermenéutico dialéctico que habilite el sumergirse en ese objeto de estudio inasible pero que puede percibirse a partir de los objetos o sujetos que son atravesados por el tiempo. Aquí cobra importancia el concepto de rizoma y su transformación a "tiempo rizomático". Recorrer autores que nos aportan sobre la enseñanza del tiempo histórico y la complejidad de la enseñanza sobre este metaconcepto nos llevaría una extensión mayor a las posibilidades de este texto. Nuestra selección va en torno a encontrar los argumentos para fundamentar nuestro ejercicio metodológico. Joan Pagès y Antoni Santisteban expresan que

\begin{abstract}
... el tiempo es un concepto de gran complejidad y sólo lo podemos comprender desde una mirada amplia y transdisciplinar. El tiempo está presente en nuestra vida, una vida organizada alrededor del reloj, los horarios y el calendario. El tiempo está presente en nuestro lenguaje y nuestras actividades: esperamos, desesperamos, hacemos tiempo, perdemos, recortamos, alargamos el tiempo, damos o nos toman tiempo. El tiempo pasa rápido y lento, se acelera o, incluso, ¿se detiene? El tiempo es historia, la nuestra y la de todas las personas, es pasado colectivo, es interrelación de pasado, presente y futuro. ¿Cómo sabemos del tiempo? Sabemos que el tiempo pasa porque observamos los cambios en nuestro cuerpo o a nuestro alrededor... (Pagès y Santisteban, 2010:282)
\end{abstract}

El tiempo podría representarse en tres palabras, en el nombre de tres dioses: Kronos, Aión y Kairós (Nuñez, 2007). La narración que aporta este autor en torno a los dioses es otro aporte para nuestra preocupación. Cronos es el devorador, el transcurrir la finitud, es el tiempo que transcurre entre el nacer y el perecer. Aión la perfección de la vida, la serpiente que se muerde la cola, el ciclo, la repetición y el volver a comenzar. El futuro y el pasado liberados del presente, niño y viejo a la vez. Es el eterno retornar, la vida sin muerte, la plenitud, el tiempo del placer y del deseo. Dos dioses, Kronos el tiempo del reloj y Aión, donde el reloj desaparece. Entre ellos Kairós, un dios menor, dios cercano a los mortales porque “[...] necesitamos de intercesores para no sólo nacer y morir. Por ello Kairós es nuestro dios más propio. El pliegue, el lugar donde se unen y donde podemos distinguir el tiempo de la supervivencia entre muerte y muerte; y el tiempo de la vida plena donde no hay muerte [...]" (Nuñez, 2007:5).

La historia no se cuenta por Kronos, se cuenta por Kairós, hay temporalidades que no pasan, y que ésas son las que nos constituyen. Los tiempos de esa historia deja marcas que precisan de interpretaciones. No estudiamos el sucederse de los acontecimientos, sino que reordenamos la historia e incluso la narración de nuestra propia vida a partir de las marcas. Pero ¿cuáles son las temporalidades que se inscriben dentro de otras, si esas marcas son todas subjetivas?, ¿cómo construir un relato que enlace o entreteja nuestras vidas finitas? ¿Cómo enseñar acerca de la historia, de los hombres y mujeres en su devenir de tiempos rizomáticos? Y en esto consiste la búsqueda, en encontrar aquellas marcas que superan nuestras individualidades, que a la vez nos contiene, es decir los hitos que nos involucran desde lo colectivo sin negarnos subjetivamente. Desde la perspectiva didáctica pretendemos involucrar a nuestros estudiantes en esos rastreadores de marcas y lectores de temporalidades heterogéneas y múltiples. 
En esa reconstrucción de pliegues del tiempo entendemos que se avizora la posibilidad de tiempos futuros, de proyección, del reconocimiento de nuestra finitud, pero también de la necesidad de continuidad en un tiempo en el que no seremos, pero que precisó de nosotros para su despliegue. De aquí que la posibilidad de futuro dependa de la creación y descubrimiento de marcas, del sentido de la historia o mejor dicho del sentido de cada uno de nosotros en la historia. De aquí por tanto se sustenta la perspectiva ético-política-estética de la enseñanza de la historia que proponemos desarrollar

\section{De la imagen como ilustración a la imagen como narración acerca del tiempo}

El conjunto de imágenes incesantes (la televisión, el vídeo continuo, las películas) es nuestro entorno, pero a la hora de recordar, la fotografía cala más hondo. La memoria congela los cuadros; su unidad fundamental es la imagen individual. En una era de sobrecarga informativa, la fotografía ofrece un modo expedito de comprender algo y un medio compacto de memorizarlo. La fotografía es como una cita, una máxima o un proverbio. Cada cual almacena mentalmente cientos de fotografías, sujetas a la recuperación instantánea... (Sontag,2003:14)

Nuestra indagación surge de la observación e interpretación de dos cohortes de practicantes del profesorado en Historia (años 2018 y 2019) en las que prestamos especial atención al uso de la imagen por parte de los estudiantes. Todos los practicantes utilizaron imágenes fijas, pero en su mayoría su uso tuvo un predominio ilustrativo y la urgencia y la escasez del tiempo áulico para desplegar sus propuestas de enseñanza, eligieron el trabajo con textos escritos y dejaron las imágenes como complemento e ilustración del tema en estudio. Reconocemos que la intención fue usar la imagen, pero se evidenció que ellos seguían dando más potencia de enseñanza al texto escrito. De esa situación surgió nuestra búsqueda de cierto modelo, no para ser repetido sino para proponerlo a modo de pattern, de guía metodológica.

Pensamos en la idea de modelo o patrón para abordar la enseñanza del tiempo a través de la imagen. Nos remitimos aquí, de algún modo, a la búsqueda de modelos como desafío de la didáctica. En un trabajo sobre enseñanza y aprendizaje sobre el tiempo, Santisteban (2007) realiza aportes fundamentales sobre avances en la construcción de un modelo conceptual acerca de la enseñanza del tiempo. Es en este sentido que pretendemos sintetizar una propuesta metodológica para la enseñanza acerca del tiempo histórico, pero en nuestro caso el desarrollo del modelo se centra en el uso de imágenes. El desafío es abordar la enseñanza del tiempo, pero de un tiempo diverso, de temporalidades varias, interrumpido, que se simboliza en el rizoma y a la vez proponer un abordaje práctico desde un posible pattern, patrones que colaboren en la organización de información y la interpretación en el tratamiento de las imágenes como componentes de la narrativa histórica.

[...] la historia como ciencia que interpreta este pasado no ha aportado un modelo conceptual que nos permita elaborar un currículo para la enseñanza del tiempo histórico. El papel de la didáctica de la historia consiste en proponer un modelo conceptual sobre el tiempo, una síntesis de las diversas aportaciones para, en este caso, la enseñanza de la historia en la escuela primaria. (Pagès y Santisteban, 2010:284) 
Tiempo y narrativa se conjugan para nosotros en las narrativas visuales como complemento para la formación del pensamiento visual y el desarrollo de las competencias estéticas (componente de la formación planteado en las propuestas STEAM $+\mathrm{H}$ de Unesco ODS2030). La formación en la "experiencia estética" (Dewey, [1934]2008) profundiza el desarrollo de la sensibilidad, reclama la necesidad de investigadores sensibles y repone la conexión arte-ciencia.

Las narrativas visuales son una posibilidad de entrada a la formación de profesorado en Ciencias Sociales con atención a la estética. La propuesta metodológica es "abrir el pliegue exacto en la relación entre imagen e historia" para reconocer el anacronismo como desestabilizador, generador del conflicto (Didi Huberman, 2011:144). La tesis de Didi- Huberman es la siguiente: se produce transmisión a través de las imágenes y esto se puede observar a partir de las supervivencias que hay en éstas, las cuales obedecen a un tiempo que se desmonta en presencia de elementos de tiempos distintos en una misma imagen. Se revela la importancia de la imagen en tanto se construye de múltiples pasados, en un presente, " [...] es una imagen lo que libera primero el despertar [...] en la imagen el ser se disgrega: explota y al hacerlo, muestra- pero por muy poco tiempo- el material con que está hecho. La imagen no es la imitación de las cosas, sino el intervalo hecho visible, la línea de fractura entre las cosas [...]" (Didi Huberman, 2011:166).

Avancemos entonces en el detalle de los cuatro ejercicios que comenzamos a proponer en la cohorte 2020 (y que la pandemia se encargó de hacer necesarios). Les propusimos revisar las notas que describen cada ejercicio, que eligieran uno y lo llevaran a cabo a partir de una secuencia de imágenes que respondan al problema/tema de la secuencia didáctica a desarrollar. La selección de imágenes se circunscribe al ejercicio elegido y de allí se desarrollan luego las consignas que guiarán en la comprensión e interpretación del contexto representado visualmente. Posteriormente los estudiantes podían aportar otras fuentes o textos escritos.

Ejercicios de narrativas visuales:
a) Zoom.
b) Piezas de un puzzle.
c) Traslaciones.
d) Series visuales.

a- Hacer "zoom", sobre una imagen para que la activación del lente y por tanto que la ampliación del campo active la observación. Desarrollar la atención y la observación como preparación para la formulación de problemas históricos. Para este ejercicio, tomamos la idea de una obra Istvan Banyai (1995), en la que se propone el ejercicio de zambullirse en la imagen y descubrir las capas que se ocultan tras la primera mirada. En cada imagen hay hilos conducentes que arrastran el ojo a las profundidades del espacio y el tiempo. El libro "zoom" en sus imágenes hilvana y ensambla ese collage para dar cuenta de las temporalidades y territorialidades. El cambio de perspectiva que posibilita ampliar el foco abre a desocultamientos, a la identificación de conexiones, posibilita múltiples lecturas en una misma imagen. Nos hace conscientes desde dónde nos paramos, qué vemos a simple vista y si estamos dispuestos a ir por más. ¿Estamos dispuestos a 
descubrir? Esa ampliación de observación se dedica al detalle, a la lectura ampliada y expandida de una imagen.

Tanto en el caso de la fotografía como en el caso de la pintura este ejercicio posibilita la inclusión de los elementos que componen un contexto, tanto a partir del ojo del fotógrafo que selecciona qué y desde que perspectiva enfocar, como desde la creación del pintor que incorpora y resalta tal o cual objeto y personas para representar en su obra. En este ejercicio destacamos la importancia del desarrollo de la percepción y de la importancia de atención al detalle, de encontrar contenido, densidad e información dentro de esa imagen que se presenta en dos dimensiones a simple vista pero que puede desmontarse en rizomas de temporalidad. Observar, imaginar, recordar, asociar temporalidades, serán algunas de las posibilidades que se conectan con el zoom de cada imagen. Desde la enseñanza de las Ciencias Sociales estamos trabajando sobre otras formas de lectura, la lectura de imágenes, por tanto, la lectura de otros formatos textuales que se conectan con las culturas juveniles contemporáneas. En suma, encontrar las conexiones entre desarrollo del pensamiento visual y el pensamiento histórico.

b- Las "piezas de un puzzle". Las partes y el todo entran en conexión para que el reconocimiento de los retazos y fragmentos encastrados expliquen y promuevan interpretación de un contexto y nos hablen de los hombres y mujeres que vivieron en un determinado fragmento cronotópico. Usamos el vocablo en inglés para no acentuar la idea de "romper cabeza" según la traducción en castellano. Preferimos la idea de encastre, de búsqueda de conexiones, incluso la idea de confusión y necesidad de encontrar el significado de algo, de descubrir un enigma, un misterio. Este ejercicio invita a conectar componentes de un determinado contexto temporo-espacial o a la combinación cronotópica que permiten realizar la secuencia de imágenes. "Mirar es hacerse cargo de lo que pasa en el exterior y el ojo es el medio para operar ese gesto. Y mirar más de lo debido conlleva siempre un riesgo de sanción" (Santoro, 2019:96).

Pensar la enseñanza y el aprendizaje de las Ciencias Sociales desde una perspectiva cronotópica implica dar densidad a las coordenadas temporo espaciales. Este cruce de tiempo (cronos) y lugar (topos), es una posibilidad para pensar que nuestras coordenadas tiempo y espacio son tan diversas que sería imposible captarlas en un simple cruce, sino que el ejercicio de pensar en diversos escenarios, en diversos lugares en los que suceden distintas situaciones y cómo a los diversos sujetos que son parte de un contexto son atravesados por el mismo tiempo, pero con vivencias distintas. Pensar 2021 en Argentina no es idéntico para todos los argentinos, desde una mirada cronotópica podemos reflexionar en la sincronía de vivencias. Ante el índice de pobreza del $42 \%$ y de un $10,5 \%$ para la indigencia en el segundo semestre 2020, surgen preguntas acerca de cómo se encastran esos datos con la cifra que completaría el 100\%, más dolor produce el reconocimiento que dentro de ese $42 \%$, el $57.7 \%$ son niños de $0-14$ años. Estos datos accesibles en INDEC nos permiten hacer un ejercicio de encastres, preguntas, dudas, pensar las causas, las incidencias a futuro de esta realidad local según las distintas condiciones de vida en los que los argentinos vivimos el primer año de pandemia. La advertencia es clara, no podemos pasar inadvertidamente ante el "dolor de los demás" (Sontag, 2003). "De hecho, son múltiples los usos para las incontables oportunidades que depara la vida moderna de mirar -con distancia, por el medio de la fotografía- el dolor de otras personas" (Ibídem:10). 
Las cifras y las infografías no son imágenes de guerra o de genocidios como las que llevan a las reflexiones iniciales de la autora, aparecen como una fotografía incruenta. Detrás de esos números hay hombres, mujeres, de distintas edades y que viven en nuestro mismo tiempo.

Ese ejercicio sincrónico que planteamos rápidamente es un ejercicio cronotópico que puede trasladarse al pasado en búsqueda de mayores conexiones y que en la propuesta que hoy desarrollamos tiene como soporte a la imagen como fuente-recurso que promueve esa reconstrucción. Así como los seres humanos que encontramos en todos los textos de historia, no todos vivieron de la misma manera los procesos que estudiamos. Pretendemos que este ejercicio promueva la imaginación histórica, el trabajo desde la sincronía y las infinitas posibilidades de búsqueda de explicaciones. El texto citado nos provee de elementos para profundizar. "Las fotografías son un medio que dota de «realidad» (o de «mayor realidad») a asuntos que los privilegiados o los meramente indemnes acaso prefieren ignorar...” (Sontag, 2003:8).

c- El tercer ejercicio, "traslaciones", propone trabajar desde una situación del presente para problematizar las huellas del pasado que se detectan a modo de un "bucle" temporal que reaparece en el presente como una traslación. Este ejercicio nos permite el trabajo con sincronías, diacronías, rupturas y múltiples entradas, en especial en aquellas representaciones visuales que guardan en sus pliegues referencia a obras del pasado. Aquí el desafío es pensar la enseñanza de la historia a partir del presente.

El presente no es un tiempo homogéneo, sino una articulación chirriante de temporalidades diferentes, heterogéneas, polirrítmicas, ... hojaldrados de la temporalidad y de la historicidad... un fenómeno que da al pasado de las sociedades un extraño dejà vu, de algo que retorna, por lo menos en apariencia...repetición de las situaciones...de los argumentos ...los eslóganes...las retóricas...de las derrotas de los humildes, de los humillados y los ofendidos, repetición de las dominaciones [...] (Robin,2014:41).

Detectar en el presente las señales del pasado que se cuelan nos permite generar el proceso disruptivo y la advertencia para internarse en un viaje a ese fragmento del pasado y posteriormente reconocer que ya no es ese mismo presente el que se observa. Esa señal de disrupción nos traslada a otro tiempo para poder reinterpretar el presente, ejercicio dialéctico que consideramos, puede ser una opción para la educación histórica, política y ciudadana. Es urgente porque esa imagen del pasado, de lo sucedido, de lo no visibilizado, lo olvidado, forma parte del presente, pero, "la verdadera imagen del pretérito pasa fugazmente" (Benjamin, 1947, Tesis V). Descubrir los pliegues del tiempo manifestados en las narrativas visuales, porque "siempre ante la imagen [...] estamos ante el tiempo" (Didi Huberman, 2011:31).

La idea de bucle temporal y temporalidades fragmentadas está presente en los consumos culturales actuales, series, films, videojuegos, pero también lo está en muchas publicidades, en murales callejeros, en performances artísticas que desde el presente llaman a representaciones del pasado y producen una conexión a interpretar.

No es que de repente el pequeño espíritu humano debe ser teletransportado a una esfera global que, de todas maneras, sería demasiado vasta para su pequeña escala. Más bien se trata que debemos deslizarnos, envolvernos en un gran número de bucles, de 
suerte tal que progresiva, gradualmente el conocimiento del lugar en que residimos y los requisitos demuestra condición atmosférica pueda ganar una pertinencia mayor y ser percibida como más urgente[...] ser envueltos en forma de bucles es lo significa "ser de esta Tierra”[...] una después de cada paso de un bucle nos volvemos más sensibles y más reactivos a las frágiles envolturas que habitamos (Latour, 2017:161).

d- Las "series visuales" como integradoras de tiempos rizomáticos. La idea de la serie visual se desprende de la posibilidad de pensar que quien construye una serie actúa como quien produce un film, un argumento que se despliega en movimiento. La propuesta consiste en integrar un conjunto de imágenes que, si bien no tendrán la velocidad ni la sumatoria de imágenes que compone un film, tiene como objetivo generar una sucesión diversa que proponga un argumento en el que sumen diversos cortes temporales, por tanto, diversos sujetos y espacios. La serie visual, en nuestro caso se asemeja a una percepción dispersa a una yuxtaposición de partes. Como ejercicio para la enseñanza del tiempo histórico, la propuesta de pensar una serie visual intenta resaltar la posibilidad de pensar la diversidad temporal o al decir de Berger "[...] el tiempo, el ritmo y los bucles, las repeticiones de una canción constituyen el lugar en el que refugiarse del tiempo lineal, un refugio en el que el futuro, el presente y el pasado pueden consolarse, provocarse e inspirarse, además de ironizar juntos” (Berger y Demirel, 2018:109).

Los modos de ver y la percepción sensorial acerca del tiempo y el espacio son históricos y se correlacionan con las transformaciones tecnológicas (Benjamin, 2011:36), así es como (modestamente), nuestra propuesta de la serie invita a la creación cuasi lúdica de mostrar una sucesión no lineal sino rizomática de una narración. Una secuencia debe ser leída e incita a cambios en la atención, remitirá a distintos fragmentos temporales, a distintos sujetos, distintos espacios que serán integrados por un hilo conductor que provocará la conexión entre la secuencia. Tanto quien produce la secuencia como quien la lee participan en organizar la dispersión.

\section{Desarrollo de narrativas visuales en un recorte temático}

Para mostrar a nuestros estudiantes un posible recorrido, planteamos este a fines del año 2019. En este caso elegimos la coyuntura de finales del siglo XIX en Argentina, coyuntura caracterizada por la consolidación de los estados nacionales en América Latina, conectados a nivel regional por una expectativa de modernización en la región que se integraba al mercado capitalista mundial.

a- Zoom. Elegimos "La vuelta del malón", obra de Angel della Valle (1892) expuesta en el Museo de Bellas Artes en la Ciudad de Buenos Aires. Recuperado de https://www.bellasartes.gob.ar/coleccion/obra/6297/
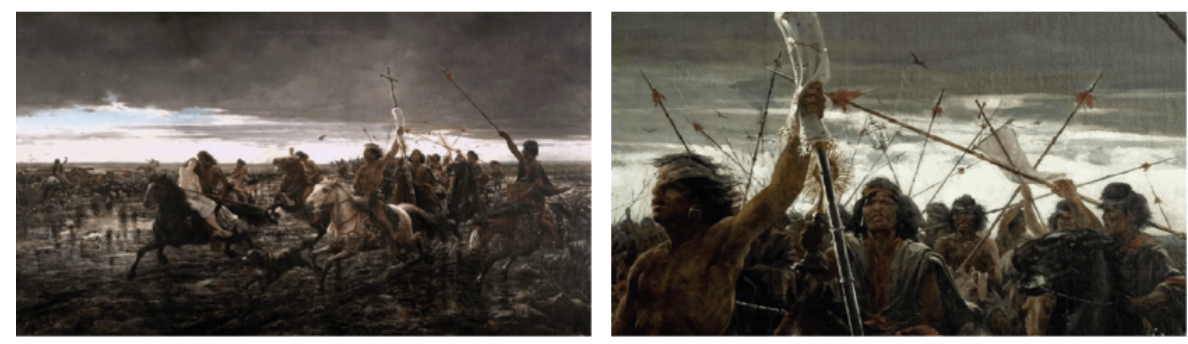

Observemos los detalles al ampliar y profundizar: 

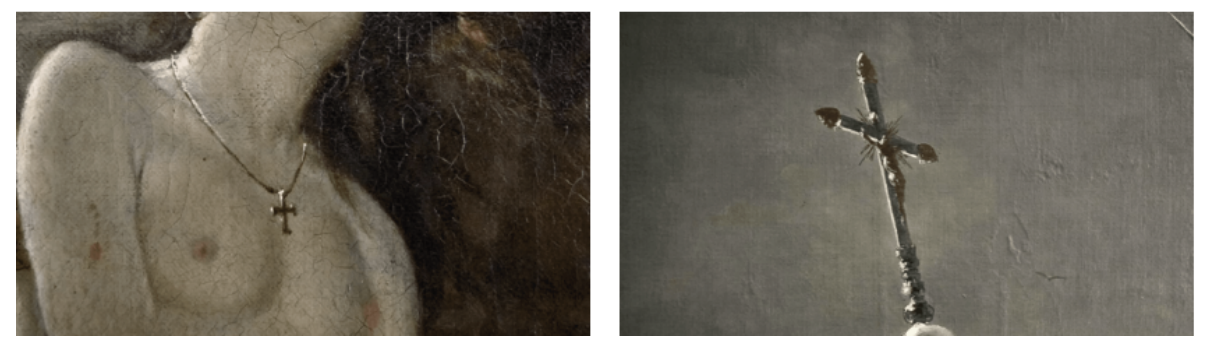

Si bien la obra ofrece múltiples lecturas y análisis, seguimos a Santoro y Fava (2019). A primera vista predomina la visión del malón, pero a medida que nos detenemos a observar encontramos otras informaciones y argumentos brindados por el pintor: las señales del ultraje a manos del malón, a la vez otros símbolos como los crucifijos, la luz en el horizonte conmemoran el triunfo del cristianismo y la "civilización".

En la descripción de la obra realizada por el museo de Bellas Artes de Buenos Aires se indica que en 1892 el cuadro fue expuesto en la vidriera de la ferretería de Nochetti y Ferrero, de la calle Florida. Podemos imaginar cómo era observado por quienes se detenían frente a la vidriera. Habían pasado 400 años del "Descubrimiento de América". La obra se llevaría a Chicago para los festejos. Aquí entonces podemos trabajar la obra desde el contexto de producción y el contexto de representación. Está presente una narrativa del pasado desde la interpretación de della Valle, aquí una de las potencialidades de la imagen, la imagen como pliegue del tiempo, momento de fractura, de diacronía (Didi-Huberman, 2011), la presencia de nosotros como observadores, de los observadores de la pintura en 1892 y la representación de quienes formaron parte del malón en un año incierto pero anterior a 1879, fecha en la que se llevó a cabo la campaña de exterminio liderada por Roca.

El regreso del malón no era posible en 1892 pero al momento de la exposición quienes observaban la pintura podrían tener en su memoria aquella campaña contra los indígenas y observarían cómo los emblemas de la civilización eran arrasados por los indios. A la vez es una advertencia de que esos bárbaros podían volver quizás ya no como indígenas, pero si quizás con otros ropajes. La amenaza permanente de la vuelta del malón, disciplina y genera una inseguridad. "Hay algo de nuestra identidad que está ratificándose en esa imagen" (Santoro y Fava,2019:70). La inseguridad justifica la punición y Roca se presenta como su garante.

Pero en una nueva mirada podemos leer que el autor hace aparecer el fantasma religioso, en apariencia el robo de los objetos mostraría el ultraje, pero a la vez se representa al indígena como si fuera un caballero con un estandarte, la cruz de la cautiva y la vincha que descubre un ojo, el pintor parece también anunciar el poder de la conversión, esos salvajes pueden ser convertidos por el poder de la religión. Desde la perspectiva de Santoro y Fava, en este cuadro della Valle tensiona la impronta anticlerical de los liberales de la época. Para complementar este ejercicio de "zoom" podríamos recurrir a la inclusión de las fotografías del "bautismo de indios" del álbum de Antonio Pozzo de 1879. De alguna manera a partir del zoom que realizamos sobre el cuadro de Pozzo integramos y agregamos más información, la que nos lleva a buscar más datos, interpretaciones y quizás 
otras fotografías que de alguna manera nos llevan al segundo ejercicio o a la segunda etapa de un mismo ejercicio.

b- Ensamblaje de piezas: Puzzle. ¿A dónde se dirige nuestra mirada? ¿Qué riesgos estamos dispuestos a correr? Podemos seguir observando otros elementos que completen el contexto.

Aquí la elección de las múltiples posibilidades dará cuenta de una opción temática/ historiográfica. Optamos por continuar el registro interseccional de pueblos originarios, mujeres, trabajadores (raza, genero, clase).

Episodio de fiebre amarilla en Buenos Aires, 1871 (Blanes). Recuperado de $\mathrm{h}$ ttp://mnav.gub.uy/cms.php?o=77
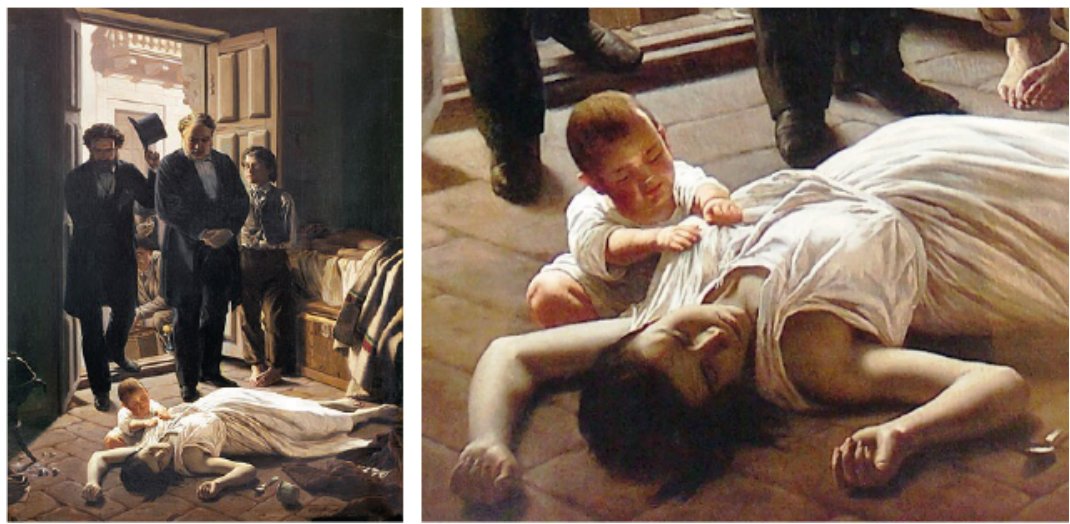

O la mujer que intenta dar de mamar a su hijo en "Sin pan y trabajo" Ernesto de la Cárcova (1894), Museo Nacional de Bellas Artes. Recuperado de https:// bit.ly/2RfjvJr

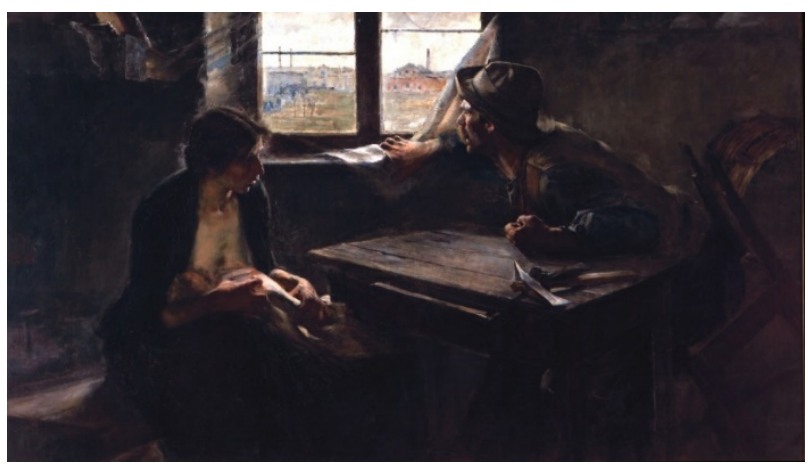

Inmigrantes, mujeres, pobreza, vidas desesperadas, desesperanzadas, cuerpos atormentados. La pintura naturalista del siglo XIX coloca y descubre los velos para pensar ese tiempo, pero también nuestro tiempo. Las pinturas elegidas para este puzzle cubren un arco entre 1871-1894. Son 20 años de retazos de un contexto que integra mujeres, inmigrantes, pobres, nuevamente la amenaza y el miedo, miedo a la muerte, al hambre, la pobreza para quienes están fuera del orden establecido por el Estado Liberal. Cuerpos indómitos y el Estado como el responsable de normalizarlos (Santoro y Fava,2019).

c- Traslaciones. Una de nuestras intenciones al enseñar a pensar históricamente es trabajar desde las historias urgentes, las que demandan atención desde el presente y que el estudio del pasado las convierte en necesarias. Esa aparición del pasado en imágenes del presente son las que nos importa rescatar en este ejercicio. 
Fotos en los Diarios de diciembre de 2019. Recuperado de https://www.lagaceta.com.ar/nota/827991/actualidad/como-45-militantesmetieron-las-patas-fuente-plaza-mayo.html
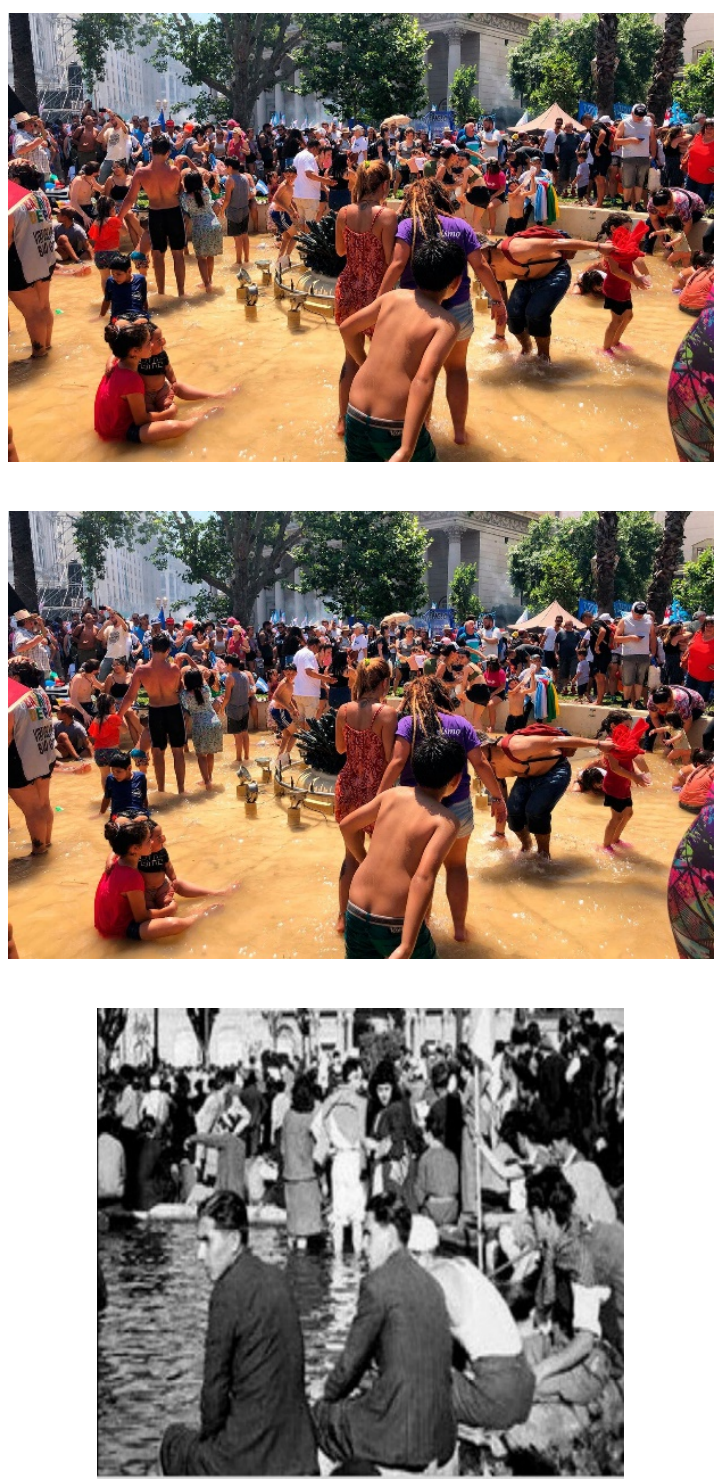

En los meses que estábamos organizando nuestra elección de imágenes se produjo la asunción a la presidencia de Alberto Fernández. El día 10 de diciembre de 2019, otro presidente peronista asumía a ese cargo, un día de intenso calor. Los militantes, los que apoyaban el acto, los curiosos se acercaron a la plaza de mayo ese día de altas temperaturas y energías. Los fotógrafos de los diarios registraron situaciones que replicaban una reconocida imagen de 1945, e incluso la titularon "militantes metieron las patas en la fuente".

Pasaron más de 60 años desde ese 17 de octubre de 1945, pero ese pasado queda allí y a modo del bucle (Latour, 2017) que no se repite pero que devuelve la imagen, nos hace preguntar acerca del efecto que esa imagen del pasado causa en quienes la miran.

Aprender a volvernos sensibles a los bucles múltiples, controvertidos, entremezclados [...] es también acercarse a la política [...] la universalidad que buscamos debe ser tejida bucle tras bucle, reflexividad tras reflexividad, instrumento 
tras instrumento [...] definir los colectivos por la distribución de las posibilidades de actuar [...] la multiplicidad está en todas partes! (Latour, 2017:163)

d- Construcción de una "serie visual". Si bien casa imagen o cada ejercicio propuesto guarda una narrativa, también podemos construir una serie para prestar atención, en este caso a la diacronía, los cambios y las continuidades a lo largo de un periodo. Ustedes podrán poner el nombre al eje de esta serie visual.
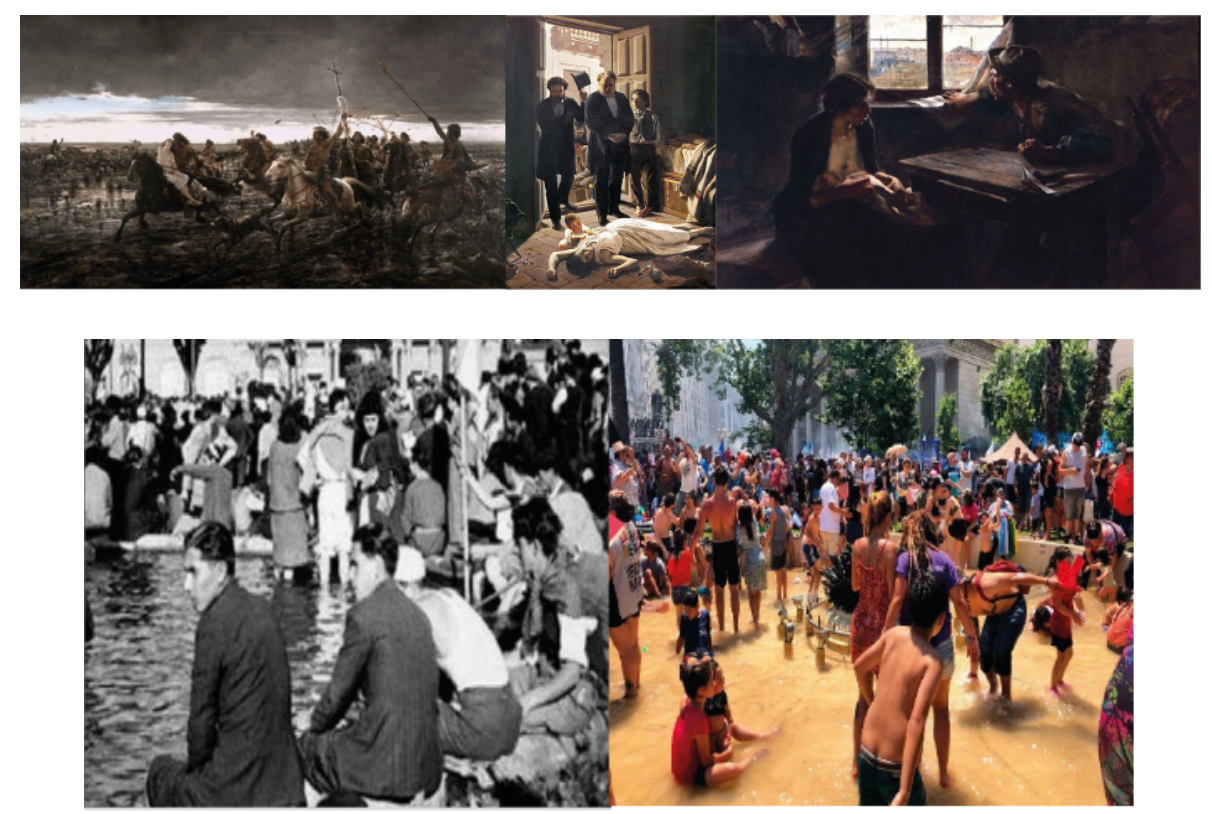

\section{Suspendidos en el tiempo}

La decisión es asirse al tiempo como hilo conector entre redes y marañas que nos sostiene como sujetos, contradictorios y diversos, sujetos sociales, con ideologías, amores y odios, con antepasados que optaron por diversos futuros. Reconocer esas posibilidades es una propuesta de cambio y abordar el estudio del tiempo a través de las imágenes. Las narrativas no lineales, la dislocación de formas tradicionales de lectura colabora, a nuestro entender con las posibilidades de enseñar temporalidades diferentes, sincronías, diacronías, multiplicidad de visiones, multiperspectivas. En este sentido propusimos estos ejercicios donde la imagen es materialización de la representación del tiempo no lineal, activadora de emociones, aprendizajes, exploraciones, búsqueda de explicaciones ante la complejidad del mundo. Como toda narración, la narrativa visual se centra en un interés fundamentado, pero implica un recorte, aunque complejo y reflexivo es un recorte de la interacción pasado presente para poder iniciar un posible análisis. Tiempo y narraciones no lineales que desde una imagen se presentan como campo de fuerzas con tensiones entre su origen y el momento en que son traídos al presente por parte de quien las selecciona y observa. Volvemos a la tesis VI de Benjamin

Hacer labor de historiador no significa saber cómo las cosas han pasado realmente. Significa adueñarse de las cosas tal y como han surgido en el instante de peligro. Se trata para el materialismo histórico de retener la imagen del pasado que se ofrece inopinadamente al sujeto histórico en el instante de peligro ... si el enemigo triunfa, 
incluso ni los muertos estarán seguros. Y el enemigo no ha cesado de triunfar. (Benjamin, 1947, Tesis VI)

Pensar la enseñanza del pasado como explicación y raíz de los problemas sociales del presente nos posiciona en el deseo de actuar como docentes ocupados por la genuina conexión entre los intereses y experiencias de vida de los estudiantes y las posibilidades de generar creativas opciones comunes de futuros posibles. Desde aquí planteamos las relaciones entre imagen, narración, tiempo y pensamiento histórico.

\section{Referencias}

Banyai, I. (1995). Zoom. México: FCE. Disponible en https://www.youtube.com/wat ch?v=JMhUujrN4iU .

Benjamin, W. ([1936]2011). La obra de arte en la época de su reproductibilidad técnica. Buenos Aires: Godot.

Benjamin, W. ([1947] 2011). Tesis sobre la filosofía de la Historia. Buenos Aires: Godot.

Berger, J. y Demirel, S. (2018). ¿Estamos a tiempo? Madrid: Nórdica.

Bruner, J. (2013). La fábrica de historias. Derecho, literatura y vida. Buenos Aires: FCE.

Deleuze, G. y Guattari, F. (1980). Mil mesetas . Capitalismo y esquizofrenia. Valencia: Pre-textos.

Dewey,J. [1934]2008. El arte como experiencia. Barcelona: Paidós.

Didi-Huberman, G. (2011). Ante el tiempo.Historia del arte y anacronismo de las imágenes. Buenos Aires: Adriana Hidalgo.

Gadamer, H. G. (1977). Verdad y Método. Salamanca: Sígueme.

INDEC. Informe técnico. Condiciones de vida. Vol. 5, 59. Recuperado de: https://www.indec.gob.ar/uploads/informesdeprensa/eph_pobreza_02_208 2FA92E916.pdf

Latour, B. (2017). Cara a cara con el planeta. Una nueva mirada sobre el cambio climático alejada de las posiciones apocalipticas. Buenos Aires: Siglo XXI.

Núñez, A. (2007). Los pliegues del tiempo: Kronos, Aión y Kairós. Paperback, 4, 2-9.

Pages, J. \& Santisteban, A. (2010). La enseñanza y el aprendizaje del tiempo histórico en la educación primaria. Cad. Cedes, Campinas, 30(82), 281-309.

Peña Timón, V. (2003). Imagen narrativa: de la imagen prehistórica a las tecnologías de la imagen. Icono 14. Revista de comunicación y tecnologias emergentes, 1, 74-93.

Pozzo, A. (1979). Album de Vistas Expedición al Río Negro. Disponible en https://museoroca.cultura.gob.ar/obra/album-de-vistas-expedicion-al-rio-ne gro-abril-a-julio-1879/

Robin, R. (2014). La memoria saturada. Buenos Aires: Walduther.

Santisteban, A. (2007). Una investigación sobre cómo se aprende a enseñar el tiempo. Enseñanza de las Ciencias Sociales, 6, 19-29.

Santoro, D. y Fava. J. (2019). Peronismo. Entre la severidad y la misericordia. Buenos Aires: Las cuarenta.

Sontag, S. (2003). Ante el dolor de los demás. Madrid: Suma de letras.

UNESCO. Objetivos de desarrollo sostenible. Recuperado de: https://es.unesco.org/s dgs 


\section{Notas}

1 Videos breves producidos por usuarios de redes sociales.

2 El desarrollo de las investigaciones en el campo alcanza las tres décadas, con particularidades regionales según ámbitos anglosajón, francófono e hispanoamericano. La difusión en revistas especializadas da cuenta de ello.

3 Grupo GIEDHiCS (Grupo de investigación en Didáctica de la Historia y las Ciencias Sociales) y Cátedra de Didáctica y Práctica de la enseñanza (Departamento de Historia), en la Facultad de Humanidades, UNMdP.

4 Referiremos en todo el texto al género masculino para facilitar la lectura, pero reconocemos en esta mención la diversidad de géneros existentes.

5 Tomamos la idea de bucle de Bruno Latour. 